\title{
BMJ Open Cohort profile: the Scottish Research register SHARE. A register of people interested in research participation linked to NHS data sets
}

\author{
Brian McKinstry, ${ }^{1}$ Frank M Sullivan, ${ }^{2}$ Shobna Vasishta, ${ }^{3}$ Roma Armstrong, ${ }^{4}$ \\ Janet Hanley, ${ }^{5}$ John Haughney, ${ }^{6,7}$ Sam Philip, ${ }^{8}$ Blair H Smith, ${ }^{9}$ Amanda Wood, ${ }^{10}$ \\ Colin N A Palmer ${ }^{11}$
}

To cite: McKinstry B, Sullivan FM, Vasishta S, et al. Cohort profile: the Scottish Research register SHARE. A register of people interested in research participation linked to NHS data sets. BMJ Open 2017;7:e013351. doi:10.1136/bmjopen-2016013351

- Prepublication history for this paper is available online. To view these files please visit the journal online (http://dx.doi.org/10.1136/ bmjopen-2016-013351).

Received 8 July 2016 Revised 23 November 2016 Accepted 3 January 2017

CrossMark

For numbered affiliations see end of article.

Correspondence to Dr Colin N A Palmer; c.n.a.palmer@dundee.ac.uk

\section{ABSTRACT}

Purpose: Recruitment to trials is often difficult. Many trials fail to meet recruitment targets resulting in underpowered studies which waste resources and the time of those who participated. While there is evidence that many people are willing to take part in research, particularly if it involves a condition from which they suffer, researchers are unable to easily contact such people often relying on busy clinicians to identify them. Many clinicians perceive themselves as too busy to take part in research activities. The Scottish Health Research Register SHARE adopts an approach which asks the public to consent to their data held in National Health Service databases to be used to determine their suitability for research projects. Additionally, participants can consent for spare blood, left after routine venepuncture to be automatically identified in the laboratory and stored for future research studies.

Participants: Anyone over the age of 16 years in Scotland can participate. Participants are approached through a range of methods including directly at outpatient clinics and general practitioners practices, leaflets with hospital letters and personal email from employers.

Findings to date: SHARE has recruited around 130000 people. SHARE has demonstrated that it can quickly and efficiently recruit to studies, over 20 until now. In addition, it can be used to administer questionnaire studies by email and recruit to patient and public involvement groups.

Future plans: SHARE continues to steadily recruit with the ambition of eventually achieving 1000000 people in Scotland. We are steadily increasing the number of data sets we use for identifying participants. We are adding a mobile app which will facilitate dissemination about research and allow the collection of physiological and activity data if desired. We anticipate that SHARE will soon become the main source of health research recruitment in Scotland.

\section{BACKGROUND}

Although randomised controlled trials remain the gold standard for interventional

\section{Strengths and limitations of this study}

- SHARE has demonstrated that it can recruit large numbers of volunteers who have intimated their interest in taking part in research, and the ability to use National Health Service linked data to identify those potentially suitable for research projects.

- SHARE has successfully recruited to projects including some 'hard to reach' participants.

- SHARE has obtained wide support from health boards, professional bodies, patient advocacy groups and the research community.

- While potentially able to exploit one of the most wide-ranging sets of data in the world, SHARE, like all similar data sets, is limited by the accuracy and completeness of clinical coding.

- Recruitment to SHARE is labour intensive and currently supported by external grant funding. Sustainability may become an issue in future if the process cannot be supported by usage payments.

medical research, recruiting participants is difficult. ${ }^{1}$ In a study by Sully et $a l^{2}{ }^{2}$ only $55 \%$ of trials recruited their originally specified target sample size, with $78 \%$ recruiting $80 \%$ of their target. There is no evidence that this has improved in recent years. Such trials are likely to be underpowered and therefore waste scarce research funding and the time of their participants. ${ }^{3}$ Although in some specialties, such as oncology, clinical trials are well integrated into day-to-day care, most people have never taken part in clinical research with few being approached and $<1 \%$ of people in the UK taking part. ${ }^{4}$ However, a census-wide poll by the National Institute for Health Research in the UK in 2014 revealed that almost $90 \%$ of people would be willing to take part in research if it was into a condition which they had 
experienced. ${ }^{5}$ Potential participants face difficulties, though, in finding relevant information on research studies in which they may be interested.

For most clinical studies, identification of potential participants relies on clinicians either opportunistically identifying potential study participants during encounters with patients or searching health records and subsequently contacting the patients on behalf of researchers to ask if they are interested in taking part. Clinicians perceive themselves as busier than ever before and many declare themselves too busy to take part in research. ${ }^{6}$ Moreover, even when clinicians do agree to recruit to a study, they often use their knowledge of the patient to decide not to offer participation in a trial because they perceive that the patient will either not respond or decline. ${ }^{7}$ The next step in the standard process is that participants then have to respond to their clinician or directly to the researcher when often a baseline visit is required to confirm eligibility. Increasingly, a genetic profile may also be required. Each stage represents a challenge to recruitment, reducing participation rates at each point.

Attempts to make this process more efficient include the setting up of registers of patients who have declared an interest in taking part in research. Academic healthcare providers have developed mechanisms to invite patients but these are often disease-based registers set up by institutions, with some linkage to the institution's data sets or by commercial organisations focused on drug discovery, offering incentives such as medication information in return, but who rely on self-declared medical history. ${ }^{8} 9$ National programmes such as "Care. Data' attempted to make use of information held on National Health Service (NHS) England linked data sets to identify people who might be suitable for studies. Care.Data assumed consent unless patients actively opted out of sharing data. This led to protests from some members of the public and the British Medical Association ${ }^{10}$ which were escalated by some high profile errors in the early stages of the project. ${ }^{11}$ The project was subsequently suspended.

\section{SHARE}

The Scottish Health Research register SHARE adopts an approach which seeks individual consent to be approached to participate in research from the outset. Since inception in 2011, about 130000 individuals have registered either by paper form or online at http://www. registerforshare.org.uk (figure 1).

SHARE asks potential participants to allow their information currently held in NHS data sets to be used securely to identify research studies for which they may be suitable (see figure 2). This is facilitated through the use of the Community Health Index (CHI) number which is the unique patient identifier used for interactions in the Scottish health service. ${ }^{12}$ Participants' contact details are regularly updated in SHARE through regular downloads from their primary care practices and removed if they die or leave Scotland. Participants can choose how they wish to be told about studies for which they may be suitable (telephone, email or letter) and how many times they wish to be contacted each year (up to a maximum of 4). Currently, SHARE is using mainly hospital discharge data and prescribing data to identify potential participants for studies as these are considered most accurate, but we intend to make use of other data sets including data from general practitioners (GPs) as they become available.

\section{SHARE- genomics}

Following on the success of a Wellcome Trust funded project Genetics of Share (goSHARE), which had successfully been run as a pilot in NHS Tayside, SHARE participants are now additionally given the option to give consent for blood remaining after routine tests have been performed, to be stored and subsequently used for approved medical research. This makes use of an automated system, running within NHS laboratories, which uses the CHI number to identify and automatically collates and stores, at $-80^{\circ} \mathrm{C}$, participants' residual routine haematology samples, until $10 \mathrm{~mL}$ has been collected (see figure 3). The collated samples can then be used for research linked to the participant's medical history. Providing ethical approval has been granted, this also allows for the use of novel biomarkers including genomics to prescreen and enrich cohorts for stratified medical studies. Currently, over 99\% of registrants provide consent for the use of these 'spare bloods' and over 40000 blood samples have been intercepted so far.

\section{Researchers' access to SHARE}

Researchers who wish to use SHARE for recruitment can do so at two stages: first, at the time of application for research funding to see if SHARE is likely to be a suitable vehicle for recruitment; and second, following funding for recruitment. Researchers are asked to complete an online request which specifically asks about the proposed recruitment inclusion and exclusion criteria, and, if funded, confirmation of ethical approval and funding along with the proposed protocol. This request is immediately emailed to the Studies Access Committee which assesses the suitability of the research for SHARE. Approval is based on the importance and quality of the study, the likelihood that SHARE will be able to find the desired number of recruits and the capacity of the organisation to undertake the research. Priority is given to studies funded by 'eligible funders ${ }^{13}$ and commercial studies.

To optimise successful recruitment, a plan of the most appropriate data sets to search is drawn up by the SHARE team in consultation with the safe haven staff. Currently, this is often a combination of community prescribing data, and inpatient and outpatient codes, but we expect to be able to use the full range of available data sets (figure 2) in the next year when primary care 


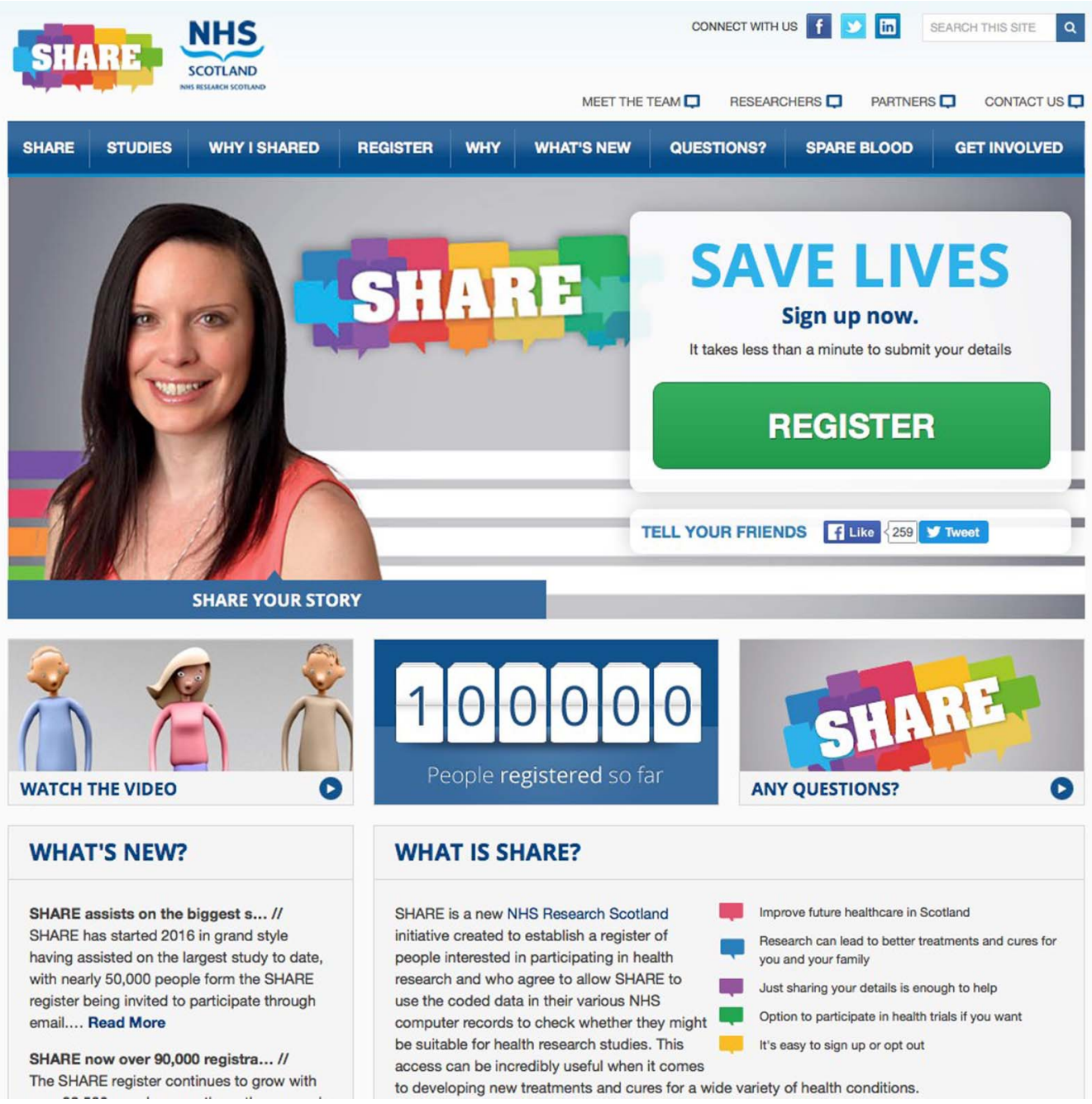

Figure 1 SHARE reaches 100000 registrants.

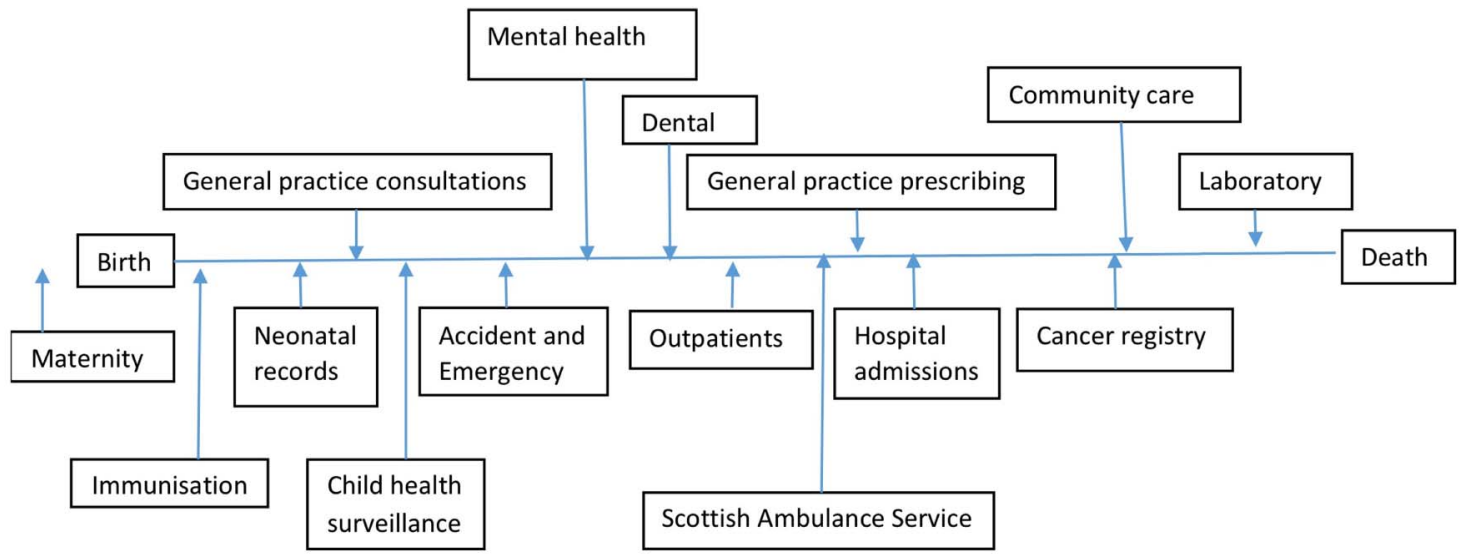

Figure 2 Scottish linked data sets. Currently, data from hospital discharges, hospital outpatient attendances and primary care prescribing data sets are those most widely used by SHARE. NHS, National Health Service.

electronic medical record data may also be included. Searches are currently carried out in local safe havens depending on where in Scotland the researchers wish to conduct their research. Once potential participants are identified, depending on their contact preferences, they are provided with details of the project by telephone, email or letter explaining that the project is one in which they may be interested. Those expressing an interest and giving consent have their contact details passed to the research team. The participant's progress is then 


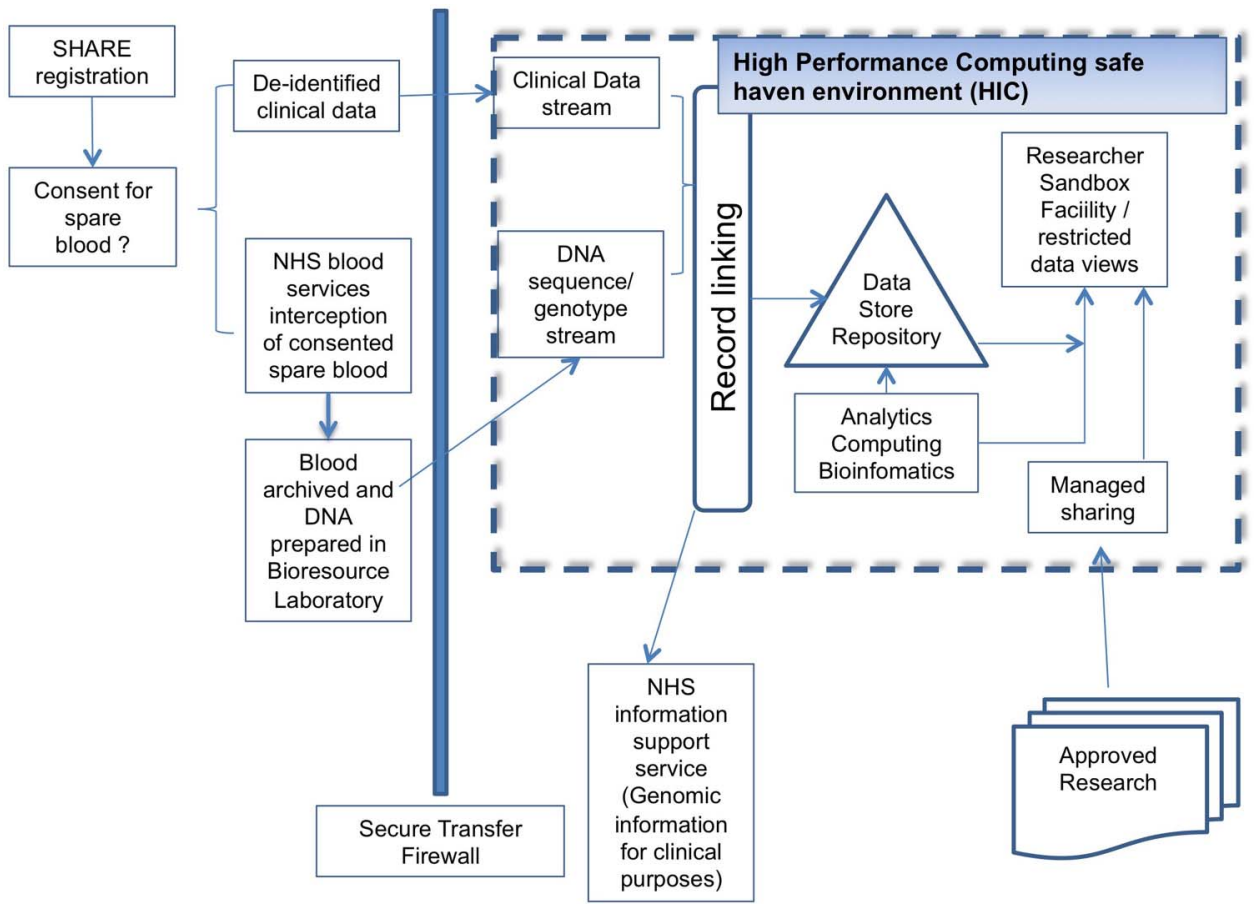

Figure 3 Interception of spare blood for genomic research using SHARE.

tracked by SHARE noting if they are recruited and then removing the ability to contact the participants temporarily from the register until their participation in the research project is scheduled to finish.

\section{Use of SHARE for public and patient involvement}

Researchers who would like to involve the general public in designing, conducting and analysing their research can do so through SHARE. The general public or people either with or without a specific disease/condition can be approached and, if willing, are put in contact with the research team.

\section{Progress}

SHARE started as a feasibility project supported by the Scottish Government Chief Scientist Office, NHS Lothian and NHS Tayside in 2011. Early research ${ }^{14}$ showed that the concept was popular with potential participants, researchers and clinicians as long as it was strongly associated with the NHS, that confidentiality was assured and that workload for frontline staff was not increased. Altruism and the hope that research may benefit either them or family members were considered major drivers to participation. Further funding from the Chief Scientist Office to build the register allowed experimentation with a variety of different forms of recruitment.

\section{Recruitment to SHARE}

Those signing up electronically indicate their main source of information about SHARE. Table 1 outlines the recruitment methods we have employed, as well as their strengths and weaknesses. Around 5\% of participants sign up online. The most cost-efficient methods of recruitment have been direct face-to-face recruitment by trained recruiters in outpatient departments (OPD) and general practice surgeries (positive response rates are around $90 \%$, with the more successful recruiters managing to recruit around 20 per hour, costing $\sim 40 \mathrm{p}$ (\$0.52) per recruit). Emails to employees from organisations (eg, university, government departments) are also successful, returning around $10 \%$ positive replies and costing very little but can only be applied once. Leaflets posted out with outpatient letters produce a similar return and are relatively low cost to SHARE (between $65 p$ and $85 p$ (\$0.87-1.18 per recruit). However, the impact of inclusion of SHARE information on letter size and weight can carry an additional cost to the NHS and in several areas have been permitted for a limited period only. Advertising on the radio, in newspapers and on buses has contributed to raising awareness. All SHARE participants are encouraged to let friends and family know through social media. Social media advertisements generated a great number of clicks but relatively few signups.

Recruitment was initially slow; however, once the most effective methods of recruitment were established and focused on, particularly face-to-face approaches, recruitment started to rise rapidly. On 2 March 2016, we recruited our 100000 th participant. Our aim is to achieve 250000 by the end of 2017 and 1 million over the next 5-10 years.

Figure 4 shows the age and sex distribution of the SHARE cohort. More women than men have been recruited. This reflects the populations attending outpatient and general practice appointments and those who accompany them. 
Table 1 Recruitment methods to SHARE

\begin{tabular}{|c|c|c|}
\hline Recruitment method & Strengths & Weaknesses \\
\hline $\begin{array}{l}\text { Face-to-face recruitment in } \\
\text { OPD and GP }\end{array}$ & $\begin{array}{l}\text { High sign-up rate (around } 90 \% \text { of those } \\
\text { approached agree to join), improves visibility of } \\
\text { research within the NHS }\end{array}$ & Labour intensive, recruiter dependent \\
\hline $\begin{array}{l}\text { Letters included with OPD } \\
\text { appointments }\end{array}$ & $\begin{array}{l}\text { Return rate } 10 \% \text {. Where accompanied by } \\
\text { personal letter from consultant, it rises to } 17 \% \text {. }\end{array}$ & $\begin{array}{l}\text { Relies on goodwill of appointments staff. Time } \\
\text { of NHS admin staff, until now, has been given } \\
\text { free but cost may be a consideration in the } \\
\text { longer term }\end{array}$ \\
\hline $\begin{array}{l}\text { Direct email from institution } \\
\text { lead }\end{array}$ & $\begin{array}{l}\text { Low cost, quick sign-up, most of whom have } \\
\text { viable email addresses which facilitates future } \\
\text { contacts. Around } 10 \% \text { sign up. }\end{array}$ & $\begin{array}{l}\text { Can only really be performed infrequently. } \\
\text { Most larger organisations prefer to advertise } \\
\text { SHARE in internal staff news magazines, but } \\
\text { this diminishes impact. }\end{array}$ \\
\hline $\begin{array}{l}\text { Advertising on Radio } \\
\text { Buses } \\
\text { Parking tickets } \\
\text { Newspapers }\end{array}$ & $\begin{array}{l}\text { Wide audience reach. Advertisements may } \\
\text { raise awareness which improves uptake when } \\
\text { participants are approached face to face. }\end{array}$ & $\begin{array}{l}\text { Expensive and not clear to what extent it } \\
\text { contributes to overall participation. }\end{array}$ \\
\hline Facebook advertisements & $\begin{array}{l}\text { Targets a younger audience than that of OPD } \\
\text { clinics }\end{array}$ & $\begin{array}{l}\text { Large numbers of website clicks but relatively } \\
\text { few sign-ups }\end{array}$ \\
\hline
\end{tabular}

Figure 4 Current age, sex distribution of the SHARE cohort.

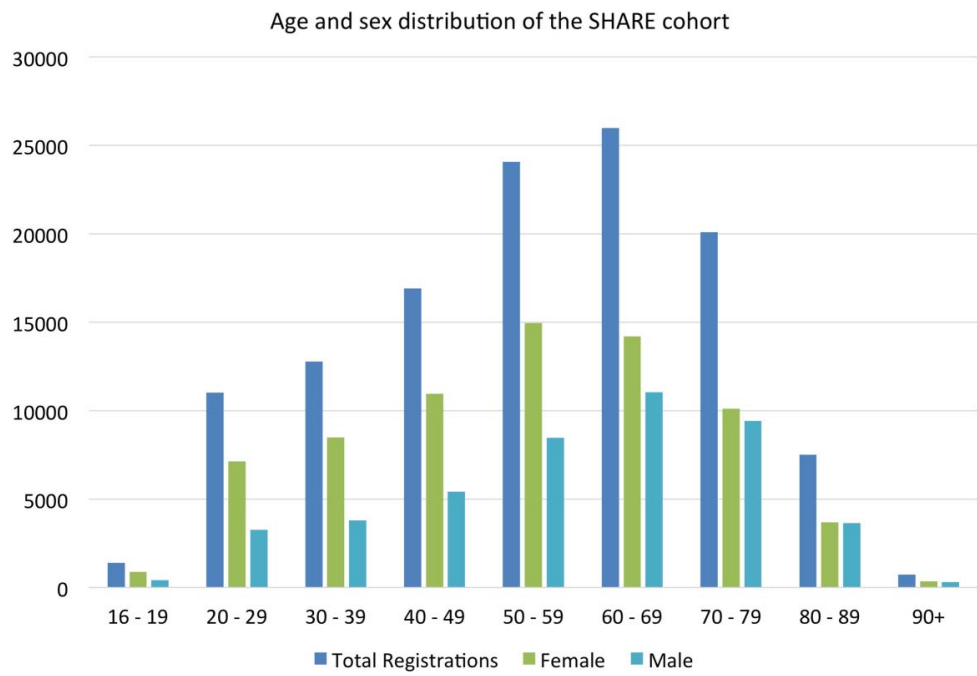

Withdrawal from SHARE

Participants are not committed to any further action or taking part in any studies and can withdraw from the register at any time by multiple routes including email, mail or telephone. Currently, 363 individuals $(0.3 \%)$ of all registrants have withdrawn from further contact and the majority of these are individuals who have become too frail/ill to be involved in ongoing/further studies. Only 33 individuals have withdrawn their consent to the use of spare blood in research. Many elderly/frail individuals who might not have felt well enough to participate in research have been very keen that they can continue to contribute to health research by the use of their spare blood.

\section{RECRUITMENT TO STUDIES}

Table 2 shows a selection of examples of the range of studies to which SHARE has recruited and the ratio of the number of approaches to positive responses and to actual recruitment. Several of these were 'rescue' procedures for studies which had failed to successfully recruit using traditional recruitment methods and were therefore particularly challenging. SHARE has now recruited to 36 studies, and currently SHARE is considering 22 new studies.

\section{ETHICS}

SHARE has NHS research ethics approval to approach patients attending NHS facilities to ask them to become part of SHARE and to use their stored data to identify them as potentially suitable participants in medical research. SHARE may only be used by applicants who have the appropriate NHS ethics approval to recruit participants to their study. The use of SHARE to recruit people to patient and public involvement panels does not require ethical approval. 
Table 2 Examples of SHARE involvement in recruitment to different types of study challenge

\begin{tabular}{|c|c|c|c|c|c|}
\hline Study & Challenge & Detail & $\begin{array}{l}\text { Number } \\
\text { approached }\end{array}$ & $\begin{array}{l}\text { Number } \\
\text { delivered to } \\
\text { researcher }\end{array}$ & $\begin{array}{l}\text { Number } \\
\text { entered } \\
\text { into study }\end{array}$ \\
\hline $\begin{array}{l}\text { SPIROA } \\
\text { The Effect of } \\
\text { Spironolactone on } \\
\text { Pain in Older People } \\
\text { with Osteoarthritis }\end{array}$ & $\begin{array}{l}\text { Required data } \\
\text { from both primary } \\
\text { and secondary } \\
\text { care }\end{array}$ & $\begin{array}{l}\text { This study sought to recruit } \\
\text { people with osteoarthritis and } \\
\text { knee pain who had not been on } \\
\text { NSAIDs, ACE inhibitors or } \\
\text { spironolactone. They required } \\
\text { eight additional participants } \\
\text { before a 2-week deadline }\end{array}$ & 25 & 16 & 8 \\
\hline $\begin{array}{l}\text { DIRECT } \\
\text { Dlabetes REmission } \\
\text { Clinical Trial }\end{array}$ & $\begin{array}{l}\text { Rescue before } \\
\text { recruitment } \\
\text { closure }\end{array}$ & $\begin{array}{l}\text { This study required recently } \\
\text { diagnosed people with diabetes } \\
\text { within } 3 \text { weeks before study } \\
\text { closure }\end{array}$ & 12 & 8 & 2 \\
\hline $\begin{array}{l}\text { DECIDE } \\
\text { Decision-making and } \\
\text { comprehension of } \\
\text { interactive and static } \\
\text { Summary of } \\
\text { Findings tables. }\end{array}$ & $\begin{array}{l}\text { Large-scale } \\
\text { survey }\end{array}$ & $\begin{array}{l}\text { Complex survey exploring } \\
\text { preferences for presentation of } \\
\text { risk which had struggled to get } \\
\text { responses. } 20 \% \text { response was } \\
\text { desired. } \\
\text { However, the survey was only } \\
\text { compatible with desktop } \\
\text { operating systems and therefore } \\
\text { was inaccessible to the large } \\
\text { numbers of registrants who } \\
\text { clicked through from mobile } \\
\text { devices. }\end{array}$ & 50000 & $\begin{array}{l}16266 \text { viewed full } \\
\text { email, } 9183 \\
\text { clicked and } \\
\text { attempted survey }\end{array}$ & $\begin{array}{l}\text { Over } 2000 \\
\text { completed. }\end{array}$ \\
\hline $\begin{array}{l}\text { H. PYLORI } \\
\text { Infection And Acid } \\
\text { Secretory Function }\end{array}$ & $\begin{array}{l}\text { Anticipated high } \\
\text { refusal rate }\end{array}$ & $\begin{array}{l}\text { Study which required } 150 \\
\text { healthy volunteers willing to } \\
\text { undergo endoscopy }\end{array}$ & 1400 & 251 & 150 \\
\hline REFORM- & $\begin{array}{l}\text { Finding people } \\
\text { with multiple } \\
\text { morbidity }\end{array}$ & $\begin{array}{l}\text { Research into the Effect Of } \\
\text { SGLT2 inhibition on left } \\
\text { ventricular remodelling in } \\
\text { patients with heart failure and } \\
\text { diabetes mellitus }\end{array}$ & 63 & 27 & 15 \\
\hline
\end{tabular}

For the spare blood samples, the appropriate accredited NHS Tissue Bank provides governance of the samples, overseeing secure sample storage, access and release. All biological information measured in these samples, including genomics, is returned to the central database to be made available for further research and potential clinical use. The full details of the information provided to registrants are available at http://www. registerforshare.org/any-questions.php\#tayside.

\section{FUNDING}

SHARE is funded by NHS Research Scotland (NRS) (http://www.nhsresearchscotland.org.uk/), a partnership of Scottish Health Boards and the Scottish Government Chief Scientist Office (CSO) that oversees governance and management of clinical research. Last year, SHARE received just under $£ 300000$ which is used to pay for ongoing recruitment, database maintenance and administration. Currently, a small cost is levied from research teams on a cost recovery basis to pay for postage and administrative time in contacting potential participants; however, a more sustainable cost recovery approach is foreseen. SHARE is based on a pilot study funded by CSO.

\section{GOVERNANCE AND OPERATIONS}

Each of the four nodes of NRS (North, South, East and West) contains informatics 'safe havens' that manage the collection and linkage of health records in a secure environment within a strong governance framework. Local Privacy Advisory Committees operate to oversee governance issues and to provide support to researchers in the design and conduct of studies. All transfers of potentially identifiable data (including the CHI number) within the NHS are conducted in accordance with local and national data security policies.

To reduce the risk of accidental disclosure, contacts with potential participants are couched in neutral terms. Contact information is carefully designed not to reveal why a potential participant has been approached for a 
particular study. If, as a result, the recruitment team is asked why contact was made, the response is that the potential participant may or may not have a condition of interest. We do not pass on any information from the medical records. Potential participants are given details about the study and told that they may be eligible to participate if the inclusion/exclusion criteria apply to them and they are interested.

Day-to-day management of the Register (awarenessraising, literature, recruitment, validation, access, the website, the database) is currently though a project management subcommittee (two directors (CP and BMcK) and project manager (SV)). Weekly meetings provide for liaison with media advisers, website programmers and an informatics lead with monthly telephone meetings of a project management group compromising representatives of all four NHS nodes. These members also provide rapid assessment of applications to use SHARE. A steering group meets twice yearly and includes management group members along with representatives of the Chief Scientist Office and a patient representative.

\section{CHALLENGES}

Current challenges include lack of access to primary care data sets and the quality of some of the data sets. The former is being addressed by the formation of SPIRE, a centralised repository of general practice data. ${ }^{15}$ Although the Scottish Morbidity Record (SMR) data are well validated, ${ }^{16}$ the coding can be limited and frequently lists only the main condition for admission with little information on comorbidities and the International Classification of Diseases 10th Revision coding may also lack the detail required. ${ }^{17}$ Health Boards frequently hold more detailed electronic data but quality can be problematic as can coding in general practice for conditions other than those incentivised by the Quality Outcomes Framework. ${ }^{18}$ However, improved access to GP records will provide information on physiological measurements such as blood pressure, weight and peak expiratory flow, which are routinely recorded.

Recruitment to SHARE is currently labour intensive and, as the register grows, maintenance will also be challenging. We are exploring ways to routinise the offer to join SHARE on registering with a general practitioner and attending hospital clinics. Although SHARE is currently supported by the Scottish Chief Scientist Office (CSO), future operations may increasingly need to be supported by charges to researchers using SHARE, aiming to be eventually self-financing.

It is only in the past year that SHARE has achieved a critical mass to be a viable source of recruitment for researchers and studies until now have largely been testing SHARE's systems. We have recently started advertising SHARE throughout Scotland and interest among researchers has risen, with a large proportion of recent funding applications to the CSO stating that intended recruitment would be facilitated by SHARE.

\section{RECENT AND FUTURE DEVELOPMENTS}

We have recently added a clinical trials portal to inform the public about research participation opportunities. This provides details of research projects by condition and by geographical area of the study and the type of participant being sought. This will allow potential participants to check some of their eligibility characteristics for these trials with a simple questionnaire and, if they meet these requirements, the option of contacting the trialists for further information and assessment. A web portal which will allow researchers to search SHARE at a high level of anonymous data to determine likely numbers of participants with particular broad inclusion and exclusion criteria for their trial is planned. This will have some appropriate limitations to ensure that searches are not disclosive, that is, that individual participants cannot be identified. We are developing a smartphone app which will provide similar functions to that above but, in addition, will be available to be used for questionnaire studies, gathering epidemiological data, participant-related outcome measures and, potentially, activity and location data if the participant permits these.

\section{CONCLUSION}

In conclusion, SHARE has demonstrated that large numbers of members of the public are willing to allow their personal data to be used to identify them for potential research projects and also for their 'spare blood' to be used for research. Altruism, and also the hope that research may benefit either them or family members and their trust in the NHS that their data will be kept confidential, underpins this. ${ }^{14}$ The register has been successful in recruiting to some more challenging studies. The register in Scotland has been established with a relatively modest amount of resource (circa $£ 300000$ (\$400 000) per annum in the set-up phase), but has demonstrated the potential to greatly facilitate recruitment to and reduce the costs of high-quality research.

For people who may wish to participate and researchers who may wish to use SHARE, details can be found at http://www.registerforshare.org.

\footnotetext{
Author affiliations

${ }^{1}$ Usher Institute, University of Edinburgh, Edinburgh, UK

${ }^{2}$ Department of Community and Family Medicine, University of Toronto,

Toronto, Ontario, Canada

${ }^{3}$ University of Dundee, Dundee, UK

${ }^{4} \mathrm{NHS}$ Greater Glasgow and Clyde, Glasgow, UK

${ }^{5}$ Napier University, Health and Social Care, Edinburgh, UK

${ }^{6}$ Division of Applied Health Science, University of Aberdeen, Aberdeen, UK

${ }^{7} \mathrm{NHS}$ Greater Glasgow and Clyde, Glasgow, UK

${ }^{8} \mathrm{NHS}$ Grampian, Aberdeen, UK

${ }^{9}$ Division of Population Health Sciences, University of Dundee, Dundee, UK

${ }^{10} \mathrm{NHS}$ Fife Victoria Hospital, Kirkcaldy, UK
} 
${ }^{11}$ Division of Cardiovascular \& Diabetes Medicine, University of Dundee Centre for Pharmacogenetics and Pharmacogenomics, Ninewells Hospital and Medical School, Dundee, UK

Funding SHARE is a NHS Scotland Research (NRS) infrastructure initiative and is funded by the Chief Scientists Office of the Scottish Government. Additional funding and initiation of the spare blood retention in Tayside was supported by The Wellcome Trust Biomedical Resource Award Number 099177/Z/12/Z.

Competing interests BMcK, FMS and CNAP are founders of SHARE.

Ethics approval East of Scotland NHS REC 13/ES/0020.

Provenance and peer review Not commissioned; externally peer reviewed.

Data sharing statement No additional data are available.

Open Access This is an Open Access article distributed in accordance with the Creative Commons Attribution Non Commercial (CC BY-NC 4.0) license, which permits others to distribute, remix, adapt, build upon this work noncommercially, and license their derivative works on different terms, provided the original work is properly cited and the use is non-commercial. See: http:// creativecommons.org/licenses/by-nc/4.0/

\section{REFERENCES}

1. Treweek S, Lockhart P, Pitkethly $M$, et al. Methods to improve recruitment to randomised controlled trials: Cochrane systematic review and meta-analysis. BMJ Open 2013;3:e002360.

2. Sully BG, Julious SA, Nicholl J. A reinvestigation of recruitment to randomised, controlled, multicenter trials: a review of trials funded by two UK funding agencies. Trials 2013;14:166.

3. Chalmers I, Glasziou P. Avoidable waste in the production and reporting of research evidence. Obstet Gynecol 2009;114:1341-5.

4. NIHR CRN Key Statistics. 2014. https://www.crn.nihr.ac.uk/ about-crn/our-performance/key-statistics-2/

5. NIHR CRN. 2014 What do people think of clinical research? https:// www.crn.nihr.ac.uk/wp-content/uploads/News/Censuswide\% 20infographic.pdf
6. van Staa TP, Dyson L, McCann G, et al. The opportunities and challenges of pragmatic point-of-care randomised trials using routinely collected electronic records: evaluations of two exemplar trials. Health Technol Assess 2014;18:1-146.

7. Thomas N, Plant S, Woodward-Nutt K, et al. Health care professionals' views of the factors influencing the decision to refer patients to a stroke rehabilitation trial. Trials 2015;16:577.

8. Harris PA, Scott KW, Lebo L, et al. ResearchMatch: a national registry to recruit volunteers for clinical research. Acad Med 2012;87:66-73.

9. Harris PA, Lane L, Biaggioni I. Clinical research subject recruitment: the Volunteer for Vanderbilt Research Program www.volunteer.mc. vanderbilt.edu. J Am Med Inform Assoc 2005;12:608-13. Epub 2005 Jul 27

10. BMA. Care data confidentiality concerns cannot be ignored, say doctors. http://www.bma.org.uk/news-views-analysis/news/2014/ march/caredata-confidentiality-concerns-cannot-be-ignored-saydoctors

11. Guardian: NHS disregards patient requests to opt out of sharing medical records. http://www.theguardian.com/society/2015/jan/22/ nhs-disregards-patients-requests-sharing-medical-records

12. Kendrick S, Clarke J. The Scottish record linkage system. Health Bulletin (Edinburgh) 1993;51:72-9.

13. Chief Scientist Office. Eligible funders. 2015. http://www.cso.scot. nhs.uk/wp-content/uploads/2013/05/NRS-Funding-Guidance-Annex2-Eligible-funders-v4.pdf

14. Grant A, Ure J, Nicolson DJ, et al. 'Acceptability and perceived barriers and facilitators to creating a national research register to enable 'direct to patient' enrolment into research: the Scottish Health Research Register (SHARE)'. BMC Health Serv Res 2013;13:422.

15. National Services Scotland. The Scottish Primary Care Information resource. http://www.spire.scot.nhs.uk/

16. http://www.ndc.scot.nhs.uk/Data-Dictionary/SMR-Datasets// SMR-Validation-Section/

17. de Lusignan S, Liaw ST, Krause P, et al. Key concepts to assess the readiness of data for international research: data quality, lineage and provenance, extraction and processing errors, traceability, and curation. Contribution of the IMIA Primary Healthcare Informatics Working Group. Yearb Med Inform 2011;6:112-20.

18. Doran T, Kontopantelis E, Valderas JM, et al. Effect of financial incentives on incentivised and non-incentivised clinical activities: longitudinal analysis of data from the UK Quality and Outcomes Framework. BMJ 2011;342:d3590. 